\title{
What Salespeople Don't Say: \\ A Review of Literature on Nonverbal \\ Communication of Salespeople: An Abstract
}

\author{
Shuang Wu and Bruce L. Alford
}

\begin{abstract}
Salespeople play a vital role in presenting information, discovering needs, and building relationships with customers. Salespeople in the service sector, retail and direct selling and industrial selling, all interact with customers directly. The communications, both verbal and nonverbal, of salespeople contribute to interaction outcomes.

Back in 1972, Hulbert and Capon (1972) suggested that interpersonal communication in marketing could be studied from the communication signs perspective. Compared to marketing research on mass communication, interpersonal communication has been less investigated. After more than 40 decades, marketing research has investigated the effects of nonverbal signals on customer outcomes, such as customer perceptions and evaluations of salespeople, customer ratings, and purchase intention (Leigh and Summers 2002; Kulesza et al. 2014; Esmark and Noble 2016). This paper intends to provide a review of literature on nonverbal signals of salespeople and reveal gaps in knowledge that could be addressed in future research. We list the nonverbal signals, study contexts, moderators, and mediators proposed in both conceptual and empirical studies in major marketing journals.

This research reviews current studies that investigate the effects of nonverbal signals on customer evaluations and perceptions in the marketing literature. Most of the studies reviewed look at the interactions between salespeople and customers in an in-store context, which is limited to face-to-face interactions. Future research can shed light on the study of interactions in other spaces such as phone call, chat, and social media. Video content can convey rich information of the communicators through auditory and visual aspects.
\end{abstract}

\footnotetext{
S. Wu $(\triangle) \cdot$ B. L. Alford

Louisiana Tech University, Ruston, LA, USA

e-mail: swu007@latech.edu; balford@latech.edu
} 